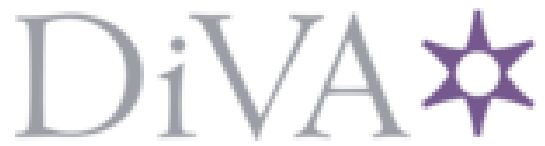

http://www.diva-portal.org

This is the published version of a paper published in Science of the Total Environment.

Citation for the original published paper (version of record):

Gong, H., Xiang, Y., Wu, J., Nkebiwe, P M., Feng, G. et al. (2022)

Using knowledge-based management for sustainable phosphorus use in China

Science of the Total Environment, 814: 152739-152739

https://doi.org/10.1016/j.scitotenv.2021.152739

Access to the published version may require subscription.

N.B. When citing this work, cite the original published paper.

Permanent link to this version:

http://urn.kb.se/resolve?urn=urn:nbn:se:kth:diva-306880 


\title{
Using knowledge-based management for sustainable phosphorus use in China
}

\author{
Haiqing Gong ${ }^{\mathrm{a}, 1}$, Yue Xiang ${ }^{\mathrm{a}, 1}$, Jiechen $\mathrm{Wu}^{\mathrm{b}}$, Peteh Mehdi Nkebiwe ${ }^{\mathrm{c}}, \mathrm{Gu}$ Feng $^{\mathrm{a}}$, Xiaoqiang Jiao ${ }^{\mathrm{a}, *}$, Fusuo Zhang ${ }^{\mathrm{a}}$ \\ ${ }^{a}$ National Academy of Agriculture Green Development, Department of Plant Nutrition, China Agricultural University, 100193 Beijing, China \\ b Department of Sustainable Development, Environmental Science and Engineering (SEED), KTH Royal Institute of Technology, SE-100 44 Stockholm, Sweden \\ ${ }^{c}$ Department of Fertilization and Soil Matter Dynamics, Institute of Crop Science, University of Hohenheim, 70599 Stuttgart, Germany
}

\section{H I G H L I G H T S}

- A knowledge-based management was used to make China's P production sustainable.

- P management can be optimized by improving the P-use efficiency in the supply chain.

- Stakeholders' sharing of responsibility and knowledge can improve sustainability.

\section{A R T I C L E I N F O}

\section{Article history:}

Received 14 September 2021

Received in revised form 4 December 2021

Accepted 23 December 2021

Available online 31 December 2021

Editor: Ouyang Wei

\section{Keywords:}

Phosphorus

Crop production

Supply chain

Food security

Sustainable phosphorus management
G R A P H I C A L A B S T R A C T

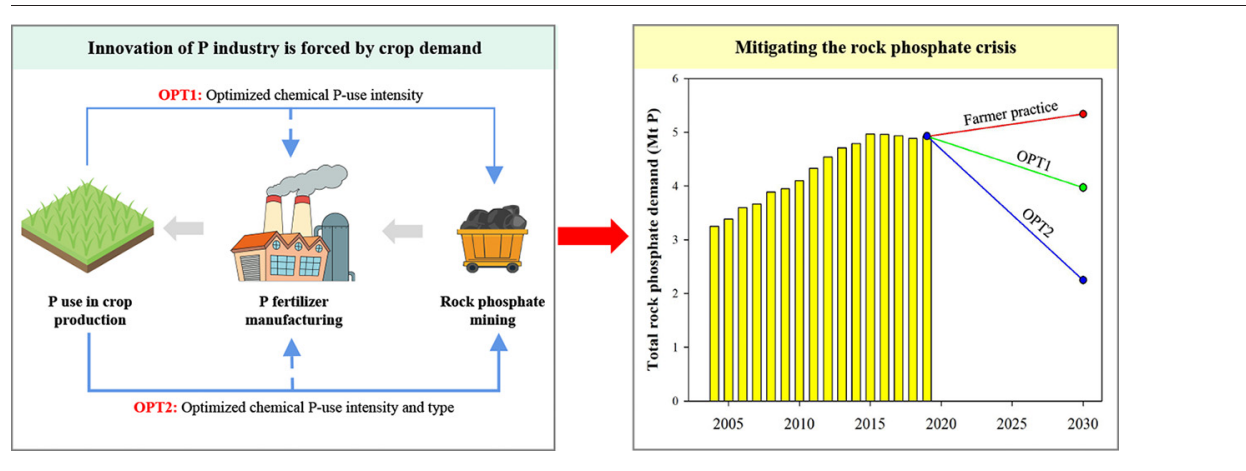

\begin{abstract}
A B S T R A C T
Sustainable phosphorus (P) management presents challenges in crop production and environmental protection; the current understanding of chemical P-fertilizer manufacturing, rock phosphate (RP) mining, P loss within supply chains, and strategies to mitigate loss is incomplete because of a fragmented understanding of $\mathrm{P}$ in the crop production supply chain. Therefore, we develop a knowledge-based management theoretical framework to analyze P supply chains to explore ways to mitigate China's P crisis. This framework connects upstream P industries and crop production, addressing knowledge gaps and stakeholder involvement. We demonstrate the potential to improve P use efficiency in the supply chain, thereby mitigating the P crisis using optimized P management. Our results showed that $\mathrm{P}$ footprint and grain production demand for RP can be reduced without yield penalty using a crop-demandoriented $\mathrm{P}$ supply chain management that integrates $\mathrm{P}$ use in crop production, $\mathrm{P}$-fertilizer manufacturing, and $\mathrm{RP}$ mining. Food security and P-related environment sustainability can be achieved by sharing responsibility and knowledge among stakeholders.
\end{abstract}

\section{Introduction}

Feeding the growing global population while ensuring sustainable phosphorus (P) use is an unprecedented challenge that the agriculture sector faces today (Chowdhury et al., 2016; Liang et al., 2020). The difficulty is not only in producing sufficient food to meet the needs of the projected global population of 9 billion by 2050 (Tilman et al., 2011; Röös et al., 2017), but also in devising an effective approach to protect the

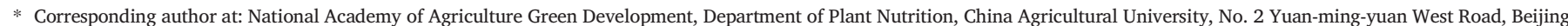
100193, PR China.

E-mail address: xqjiao526@cau.edu.cn (X. Jiao).

1 These authors have contributed equally to this work
} 
environment and reduce the reliance on finite and non-renewable rock phosphate (RP) (Simons et al., 2014). Current P management strategies face the dilemma of scarcity and rapid depletion of RP resources, as well as the low P-use efficiency (PUE) and high P-related environmental pollution (Liu et al., 2016; Luo et al., 2017). An example is the $2.5 \mathrm{Tg} \mathrm{yr}^{-1} \mathrm{P}$ loss to water and the resulting water eutrophication due to the low PUE in China (Wang et al., 2018). Improving the PUE, by methods such as optimizing the fertilizer application rate and timing and modifying advanced Pfertilizer products, is fundamental to mitigating the RP crisis (Bindraban et al., 2020; Zhang et al., 2019). Many previous studies have focused on single-factor management interventions in crop production, the efficacy of which is often limited (Li et al., 2011; Shen et al., 2011; Withers et al., 2015). Meeting this challenge calls for a transformative rather than an incremental approach to balance food security, environmental sustainability, and RP resource conservation (Brownlie et al., 2021).

Improvement of the $P$ resource use efficiency (PRE) could encompass issues of RP mining, as well as chemical P-fertilizer manufacture and its use in crop production, and requires taking a holistic and systematic, rather than a fragmented approach (Ma et al., 2011). PRE improvement requires the integration of all factors in the complete supply chain-from biophysical conditions to agronomy management practices, as well as RP mining and chemical P-fertilizer manufacturing (Chowdhury and Zhang, 2021). Hence, an effective approach to integrate the fragments of the supply chain for high PRE is urgently needed. We developed an integrated "Describe, Analyze, Design, Verify, and Action" (DADVA) framework to identify the major limiting factors for sustainable P supply chains and then implement collective action and share responsibility within such chains. Such an integrated framework and system-based approach can provide a holistic understanding of the current status and future of P management in increasing food production, conserving P resources, and addressing the environmental impact through diverse configurations of the food supply chain.

RP mining, chemical P-fertilizer manufacturing, and crop production lead to high environmental burden in China's grain production. From 1970 to 2010, a total of 56 Mt. P was accumulated through chemical Pfertilizer application in China's cropland in the pursuit of high crop yields (Sattari et al., 2014), which was more than 3.5 times the chemical P application in Africa's croplands (15.3 Mt) during the same period (USGS, 2012). An insurance, rather than precision, approach has been applied to ensure high grain yields due to limited access to advanced P management technologies (Zhang et al., 2019). Accordingly, there is a great urgency to transform $\mathrm{P}$ management strategies to reduce the environmental pollution induced by $\mathrm{P}$ and support food production (Sattari et al., 2014).

From the manufacturer's perspective, a high concentration of chemical $\mathrm{P}$ is optimum for supply because of the associated high profit and easy acceptance by smallholders (Li et al., 2016). However, because of a lack of intensive and effective dialogue between agronomists and chemical Pfertilizer manufacturing, chemical P-fertilizer is not supplied according to specific crops' P demand (Bindraban et al., 2020). Further, the plants' inherent biological potential to absorb P from the soil is largely ignored (Shen et al., 2011). These factors have caused an incongruity between chemical P-fertilizer manufacturing and crop production. Information regarding PRE in the stages of RP mining and P-fertilizer manufacturing remainslacking, and only few approaches have been shown to save $P$ resources in these stages (Zhang et al., 2008). Therefore, the challenge in China's grain production is in addressing the complexity of the biological system coupled with chemical P-fertilizer manufacturing and RP mining to ensure sustainable food security while reducing the reliance on RP mining.

In this paper, we systematically analyze the P flow from RP mining to applications in crop production and propose a potential approach to improve the PRE along the whole supply chain in order to mitigate the $\mathrm{P}$ crisis, As China plays an important role in the global P consumption, 5.0 Tg chemical P-fertilizer was input in 2017. The total chemical P-fertilizer application rates increased from 38.4 to $53.7 \mathrm{~kg} \mathrm{P} \mathrm{ha}^{-1} \mathrm{yr}^{-1}$ during 2004-2014 (Zhang et al., 2019). China produces $22 \%$ of the world's grain, but consumes $28 \%$ of chemical P-fertilizer worldwide (Jiao et al., 2016; Yuan et al., 2018). First, we quantitatively evaluate $P$ flow in China's whole supply chain. Then, we present a theoretical framework designed to be both an advanced method and collaborative action to help all stakeholders mitigate the $\mathrm{P}$ crisis through integrated crop production, chemical P-fertilizer manufacturing, and RP mining throughout the whole supply chain. Lastly, we present our projections and the potential effects on future RP demand and discuss the policy implications of our results, which can help mitigate the $\mathrm{P}$ crisis.

\section{Materials and methods}

The overall approach of this work consisted of three components: (i) a theoretical, knowledge-based management framework and integration with substance flow analysis (SFA), which was used in analyzing the P supply chains from RP mining to crop production, to explore ways to mitigate the P crisis in China; (ii) field trials, which were conducted in 2005-2014 across major agroecological zones in China to identify the problems related to chemical P-fertilizer management during crop production by farmers; (iii) a 10-year national campaign (2005-2014) across major agroecological zones and field trials that was conducted in 2017-2020, as well as a metaanalysis and survey of P-fertilizer manufacturing to develop chemical Pfertilizer optimization management by agronomists.

\subsection{System boundary and conceptual model}

This study employed a partial SFA to quantify P flows from RP to crop production. SFA is a static, quantitative model based on the mass-balance principle, and is used to quantitatively assess the flow of substance within a system (Nanda et al., 2020; Chowdhury and Zhang, 2021). Moreover, we defined three subsystems (RP mining, P-fertilizer manufacturing, and crop production) to analyze $\mathrm{P}$ flows from RP mining to consumption (see the conceptual framework in Fig. 1). P-fertilizer manufacturing includes the manufacture of a single superphosphate (SSP), triple super phosphate (TSP), and calcium magnesium phosphate (CMP) from medium-low RP processing; monoammonium phosphate (MAP), diammonium phosphate (DAP), and nitrogen-phosphorus-potassium (NPK) from high RP processing; and phosphoric acid P production. Further, 18 balance equations were established to generate the estimates of $\mathrm{P}$ flow from RP to farmlands in China (Table S1). Some coefficients were obtained from surveys conducted by an enterprise in southwestern China, which is the secondlargest chemical P-fertilizer manufacturer worldwide, and the remainder were gained from scientific literature and the National Bureau of Statistics of China. All coefficient values for the calculation are listed in Table S2.

\section{2. $P$ footprint and $P$ resource use efficiency}

The $\mathrm{P}$ footprint was defined as the amount of $\mathrm{P}$ in $\mathrm{RP}$ needed to produce $1 \mathrm{~kg}$ of $\mathrm{P}$ in grain (maize, rice, and wheat) (Zhao et al., 2019). It was calculated as

$\mathrm{P}$ footprint $=\frac{\mathrm{P}_{\text {rock }}}{\mathrm{P}_{\text {uptake }}}$

where $\mathrm{P}_{\text {rock }}$ (unit: $\mathrm{kg} \mathrm{ha}^{-1}$ ) is the total amount of $\mathrm{P}$ in $\mathrm{RP}$, and $\mathrm{P}_{\text {uptake }}$ (unit: $\mathrm{kg} \mathrm{ha}^{-1}$ ) refers to crop P removal by harvested grain.

The PRE was considered as amount of P-fertilizers recovered in the whole supply chain. The PRE was calculated as

$\mathrm{PRE}=\frac{\mathrm{P}_{\text {uptake }}}{\mathrm{P}_{\text {rock }}} \times 100$

where $\mathrm{P}_{\text {uptake }}$ (unit: $\mathrm{kg} \mathrm{ha}^{-1}$ ) is the crops' $\mathrm{P}$ removal during grain harvest, and $\mathrm{P}_{\text {rock }}$ (unit: $\mathrm{kg} \mathrm{ha}^{-1}$ ) is the P input of RP mining. 


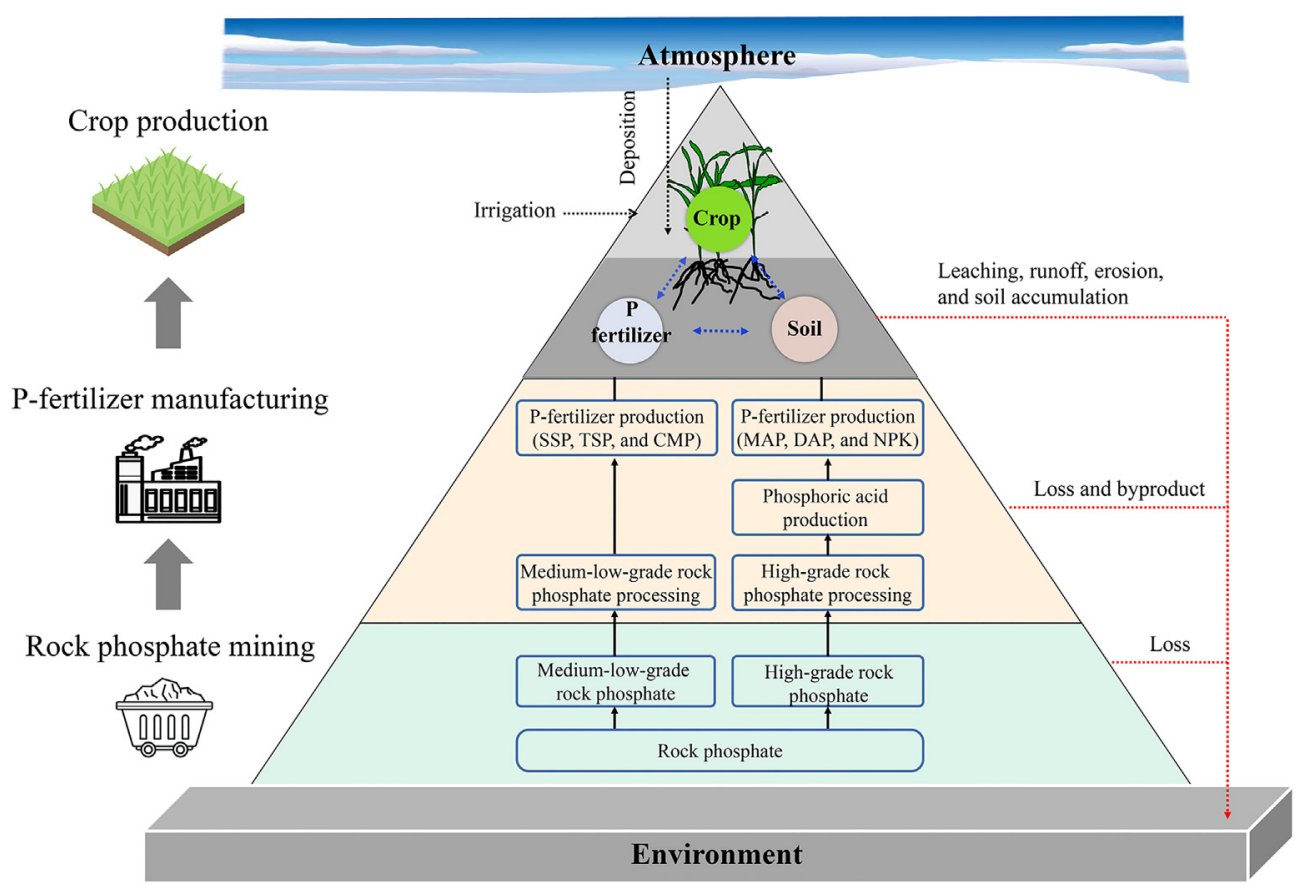

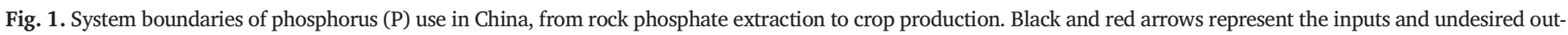

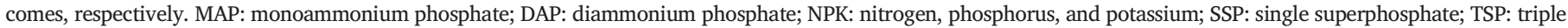

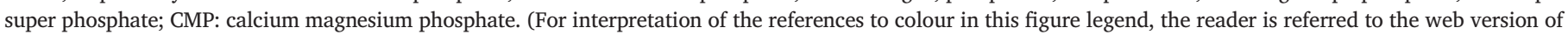
this article.)

\subsection{DADVA framework and integration with SFA}

The DADVA framework for improving P management was based on diagnosing the whole $\mathrm{P}$ supply chain, from RP mining to $\mathrm{P}$ use in crop production. The aim was not to design a completely new cropping system but rather to focus on one key aspect that needs improvement to proceed in crop production. The quantitative analysis was based on SFA, with the use of emergent data to catalyze viable and commercially attractive innovation and free access of data to all stakeholders, particularly consumers as the principal engine for change.

The DADVA cycle is an iterative method involving five overlapping steps, namely, describe, analyze, design, verify, and action, as shown in Fig. 2. (1) Describe is the essential first step and involves a descriptive diagnosis of the whole P supply chain, from RP mining to P use in crop production. P supply chains have defined system boundaries wherein all the processes are described. They have three subsystems: RP mining, P-

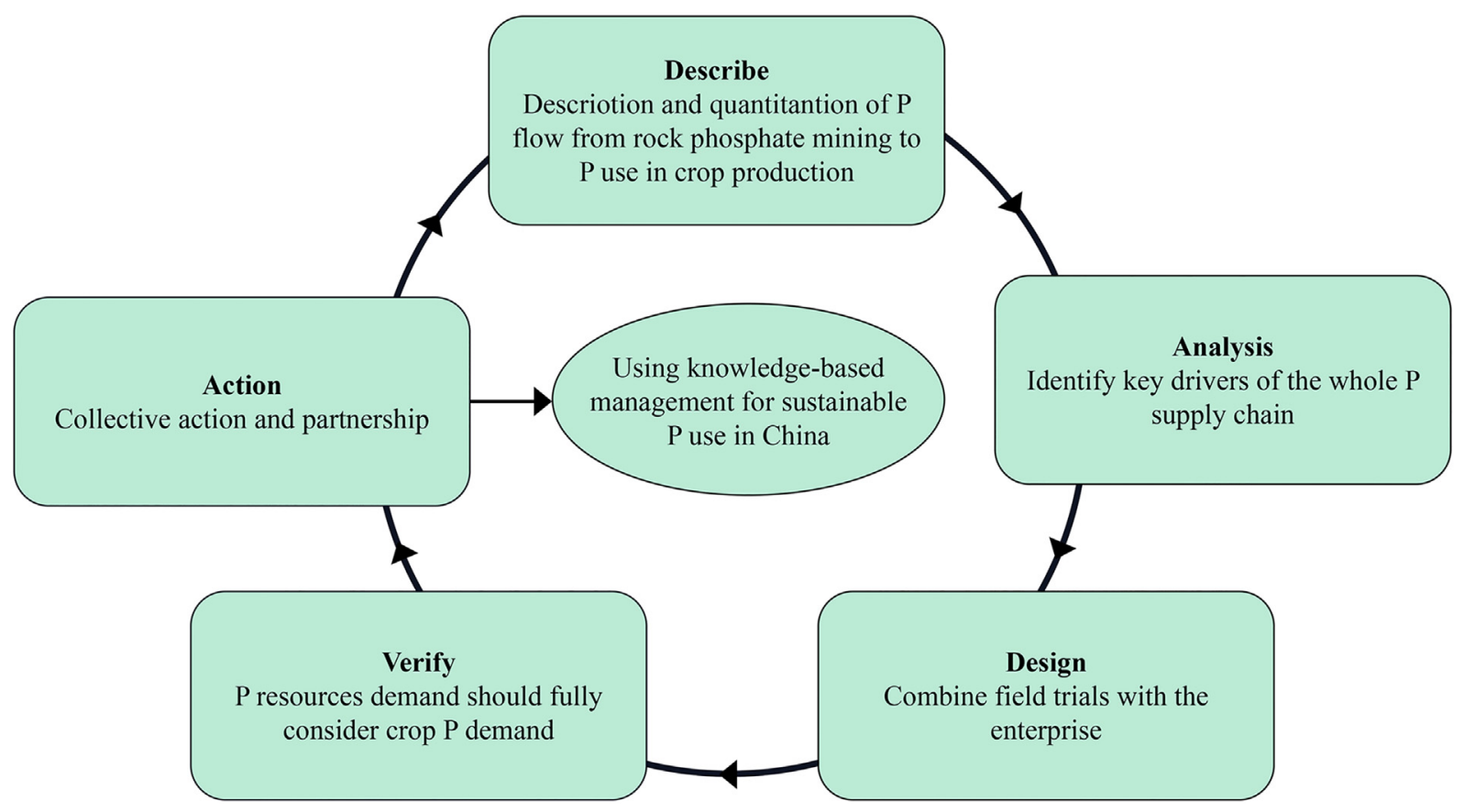

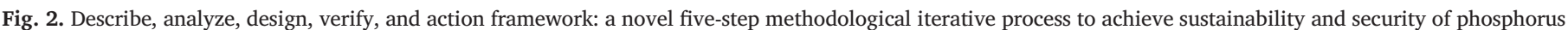
(P) management. 
fertilizer manufacturing, and crop production (Fig. 1). (2) The analyze step is necessary because, although diagnosis and quantification of the complete P supply chain are of great value, they are inadequate; analysis of P loss in the whole P supply chain can aid decision-making. Several quantitative methods are suitable for this purpose, including SFA. SFA has already been applied to $P$ supply chains and is used widely in a variety of industries to track environmental impact. (3) Design involves the development of a new P-management strategy that integrates soil-crop characteristics with chemical P-fertilizer types based on crop demand, thus contributing to sustainable P use. (4) Verify involves the assessment of the new P-management strategy through quantitative field trials under large-scale agro-ecological conditions to test its applicability. (5) Action, the final step, involves SFA and subsequent analyses to generate vast arrays of data. Integration and sharing of these data are essential because sustainable food security demands information sharing not just within the business and its supply chains but also with the government, agricultural researchers, and farmers. These data are of use to policymakers in addressing food security concerns caused by impacts on the environment (Peter et al., 2019).

\subsection{Field experiments: chemical P-fertilizer use in farmer practices}

In total, we collected 45,858 experimental observations from 296 Chinese cities, which were identified for data collection from 2005 to 2014 ( $n=18$,956 for maize, 9283 for rice, and 17,619 for wheat), with sites spread across all agro-ecological zones. Data were collected from an ambitious nationwide program called the Soil Testing and Fertilizer Recommendation Project (STFRP), which covered maize, rice, wheat, and other major crops nationwide. All sites were within a farmer's field and were managed by the farmer. Grain crops are cultivated across China in temperate to subtropical zones, and in arid to semi-arid and humid regions. The number of locations is shown in Fig. S1.

At plant maturity, approximately $5-15 \mathrm{~m}^{2}$ were harvested manually. All plant samples were oven-dried to constant weight in a forced air oven at $70{ }^{\circ} \mathrm{C}$, and grain yield was standardized at $14 \%$ moisture for all crops.

\subsection{Chemical P-fertilizer optimization management practices}

Plots at all experimental sites were separately subjected to four P treatments: 0 (control), optimal P-management strategy, below-optimal (50\% optimal P rate), and above-optimal P management (150\% optimal P rate). The optimal P management was recommended by the agronomist on the basis of local yield targets (1.1 times the average yield of the past 5 years) and soil tests, and other treatment nutrient levels were computed according to the optimum $\mathrm{N}, \mathrm{P}$, and $\mathrm{K}$ rates. All experiments were managed in the same manner as individual producers, except the implementation of fertilizer treatments and crop and soil sampling.

OPT1 was the P application rate of the optimal P-management strategy from 49,455 site-years in 296 Chinese cities for the three crops ( $n=19,252$ for maize, 16,435 for rice, and 13,768 for wheat).

Optimization management of OPT2 was estimated in two steps. First, we estimated the target yield in each city and the P rate. The target yield was the maximum yield of all fertilizer responses in the target city. If the relative yield (RY) was $<85 \%$, the recommended amount of chemical Pfertilizer for the high and stable yields was 1.3 times that of the crop. However, if $85 \% \leq \mathrm{RY} \leq 90 \%$, the recommended amount of chemical Pfertilizer for the high and stable yields was the amount taken by the crop. If RY was $>90 \%$, the recommended amount of chemical P-fertilizer for the high and stable yields was 0.7 times the amount taken by the crop ( $\mathrm{Li}$ et al., 2011).

$\mathrm{RY}$ is given as follows:

$\mathrm{RY}=\frac{\mathrm{Y}_{0}}{\mathrm{Y}_{\max }} \times 100$

where $Y_{0}$ is the crop yield of the plot without chemical P-fertilizer and $Y_{\max }$. is the maximum yield under chemical P-fertilizer.
Second, the chemical P-fertilizer type optimal for crop production was estimated. We built a database for synthesizing field research findings on the optimal chemical P-fertilizer type for crop production. Subset I: we conducted a literature search using Web of Science and China National Knowledge Infrastructure databases for relevant articles published between 2005 and 2018. Different combinations of search keyword comprise "phosphorus" together with one of the following: yield, maize (Zea mays L.), corn, rice (Oryza sativa L.), and wheat (Triticum aestivum L.). Information on chemical P-fertilizer types from the selected studies was also recorded. Studies that met the following criteria were selected: (1) data were collected through field trials on mainland China, not through pot and greenhouse experiments, (2) treatments with and without chemical P-fertilizer were included, and (3) yield and chemical P-fertilizer type data were included. A total of 282 peer-reviewed studies were identified, consisting of 1140 paired plots (320 for maize, 256 for wheat, and 564 for rice). Detailed information is provided in Appendix A. Subset II: We also assembled a supplementary dataset to compare the agronomic and morphological traits of different P-fertilizer types, and a total of 140 on-farm observations of field experiments conducted from 2017 to 2020. The number of locations of Subset I and Subset II is shown in Fig. S2. When P flow in crop production was analyzed for the chemical P-fertilizer type optimal for crop production, we found that the rates of PUE crop production were 54\%, 94\%, 96\%, 89\%, and 53\%, respectively (Fig. S3). Therefore, we chose a ratio of 50:50 as the optimal chemical P-fertilizer type for crop production through synthetical considerations.

\subsection{Data analysis}

We collected data using Microsoft Excel (Microsoft Corporation, Redmond, Washington, USA). SPSS (version 20.0; IBM Corp., Armonk, NY, USA) software was used to compute analysis of variance; significant differences among the means were determined by the least significant difference (LSD) at $P \leq 0.05$. SigmaPlot (version 10.0, Systat Software Inc., San Jose, CA, USA) software was used to generate graphics, and the results of P flow from RP mining to crop production were fed to STAN software for graphical presentation (subSTance flow ANalysis, 2.6). All map-related operations were performed using ArcGis 10.2 software (www.esri.com/en-us/arcgis).

\section{Results}

\subsection{P-fertilizer input and $P$ footprint for China's production}

China's grain production is often accompanied by a disproportionate input of $\mathrm{P}$ resources. Crop production in farmer practice (FP) consumes $43.0 \mathrm{~kg} \mathrm{P} \mathrm{ha}{ }^{-1}\left(39.9-46.5 \mathrm{~kg} \mathrm{P}^{-1}\right)$ without any yield increase, but causes a $22.6 \mathrm{~kg} \mathrm{ha}^{-1} \mathrm{P}$ loss in crop production (Table 1 and Fig. 3a, Figs. S4, S5, and S6) A saving of 30-60\% P may be achieved by optimizing P management strategy (OPT1 and OPT2), equivalent to US\$ 8.2-11.0 billion (Table 1). In China, large tracts of arable land are used for annual grain production, rather than isolated cases in field trials. Assuming the same planting area as reported in 2015 (National Bureau of Statistics of China, 2016), 23 Mt. P-equivalent to a 5-year total chemical P-fertilizer production in China-was wasted; meanwhile, $0.1 \mathrm{Mt}$. P was discharged into water bodies as $\mathrm{PO}_{4}$-eq (Wu et al., 2016). This required $€ 2.5$ billion to treat the water pollution, which equaled $1.9 \%$ of China's gross domestic product (GDP) in 2020 (National Bureau of Statistics of China, 2016; Pizzol et al., 2015).

To address the challenge of low PUE and high P loss in the supply chain, we proposed a chemical P-fertilizer optimization management approach based on crop demand. The essence of this approach is to fully consider the biological properties of crops and develop agronomic management practices based on crop demand. More importantly, we developed this approach by integrating part of the supply chain, which has great implications for where a hotspot will occur within the chain from RP mining to crop production. Cross-sector relationships between sectors, as well as the manufacture of chemical P-fertilizer, are driven by crop demand, while RP mining is driven by chemical P-fertilizer manufacturing. 
Table 1

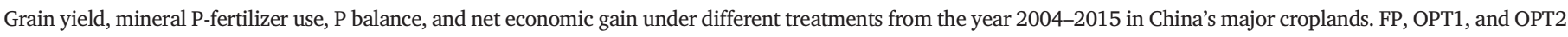

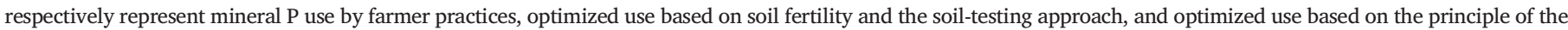
build-up and maintain approach coupled with chemical P-use intensity and types.

\begin{tabular}{|c|c|c|c|c|c|}
\hline Item & Treatment & Maize & Rice & Wheat & Average \\
\hline \multirow[t]{3}{*}{ Yield (t ha $\left.{ }^{-1}\right)$} & FP & $7.7 \pm 1.5 \mathrm{a}$ & $7.6 \pm 1.2 \mathrm{a}$ & $5.3 \pm 1.4 a$ & 6.9 \\
\hline & OPT1 & $8.7 \pm 1.9 a$ & $8.0 \pm 1.2 \mathrm{a}$ & $6.0 \pm 1.4 a$ & 7.6 \\
\hline & OPT2 & $8.9 \pm 2.0 \mathrm{a}$ & $8.3 \pm 1.3 \mathrm{a}$ & $6.2 \pm 1.4 \mathrm{a}$ & 7.8 \\
\hline \multirow[t]{3}{*}{ P-fertilizer use $\left(\mathrm{kg} \mathrm{P} \mathrm{ha}^{-1}\right)$} & FP & $42.9 \pm 14.4 a$ & $39.9 \pm 16.5 a$ & $46.5 \pm 17.0 \mathrm{a}$ & 43.0 \\
\hline & OPT1 & $36.8 \pm 8.7 b$ & $30.6 \pm 7.9 b$ & $37.9 \pm 9.4 b$ & 35.1 \\
\hline & OPT2 & $24.0 \pm 5.5 c$ & $19.4 \pm 3.4 c$ & $20.0 \pm 4.4 c$ & 21.1 \\
\hline \multirow[t]{3}{*}{$\mathrm{P}$ balance $\left(\mathrm{kg} \mathrm{P} \mathrm{ha}^{-1}\right)$} & FP & $18.0 \pm 13.6 \mathrm{a}$ & $18.2 \pm 15.8 \mathrm{a}$ & $26.9 \pm 17.7 a$ & 21.0 \\
\hline & OPT1 & $9.3 \pm 8.2 b$ & $8.0 \pm 7.4 b$ & $15.8 \pm 9.3 b$ & 11.0 \\
\hline & OPT2 & $-4.3 \pm 2.1 c$ & $-4.6 \pm 1.7 c$ & $-3.0 \pm 1.5 c$ & -4.0 \\
\hline \multirow[t]{3}{*}{ Net economic gain (billion US\$ year ${ }^{-1}$ ) } & FP & 107.0 & 93.7 & 41.4 & 80.7 \\
\hline & OPT1 & 121.0 & 98.6 & 47.0 & 88.9 \\
\hline & OPT2 & 123.9 & 102.5 & 48.7 & 91.7 \\
\hline
\end{tabular}

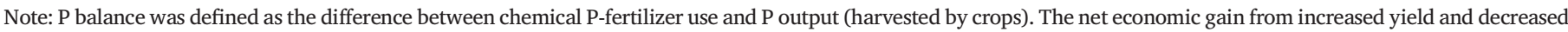

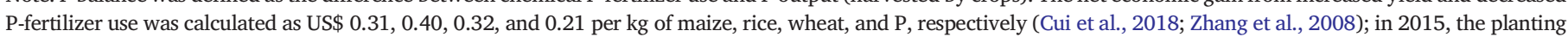
area of maize, rice, and wheat was 45.0, 30.9, and 24.6 million ha, respectively.

There were two steps in the chemical P-fertilizer optimization management approach. First, a yield-response curve was employed to identify the optimal chemical P supply to ensure a high P management yield along the whole supply chain. Second, a build-up and maintain approach combined with optimized fertilizer types was employed to identify the optimum supply intensity and types for improving the PRE via integration of all stages in the P supply chain. As wheat, rice, and maize crops often have large root systems, they can use insoluble P from the chemical P-fertilizer. The amount of RP was then calculated according to the crops' P demand.

A grain yield similar to FP was obtained through optimized use based on soil fertility and the soil-testing approach (OPT1), and optimized use based on the principle of the build-up and maintain approach coupled with chemical P-use intensity and types (OPT2) (Table 1 and Fig. S4). To produce grain yield, a large amount of $\mathrm{P}$ loss in crop production was induced by FP. To provide $6.9 \mathrm{t}$ of grain, $56.8 \mathrm{~kg}$ P from RP was used, while only $22 \mathrm{~kg}$ of $\mathrm{P}$ was used by crops, leaving $34.8 \mathrm{~kg}$ in the environment (Table 1 and Fig. 3a). As much as 59\% (20.4 $\mathrm{kg} \mathrm{P} \mathrm{ha}^{-1}$ ) of P accumulated in the soil during crop production (Fig. 3a). A similar result was obtained in India (West et al., 2014). Crop production was a hotspot of P loss. Moreover, $10.2 \mathrm{~kg}$ of $\mathrm{P}$ was lost in the chemical P-fertilizer manufacturing stage as a by-product. The PRE was only $38.7 \%$. Thus, the P footprint from grain production was $2.6 \mathrm{~kg} \mathrm{P} \mathrm{kg}^{-1}$ (Fig. 4).

China's $P$ management is important on a global scale because China produces $22 \%$ of the world's grain on less than $9 \%$ of the world's arable land (Liu et al., 2010), while it consumes $30 \%$ of chemical P-fertilizer and conducts 49\% of RP mining (Jiang et al., 2018; Zhang et al., 2008). Therefore, P-fertilizer management requires cooperation between stakeholders from crop production, chemical P-fertilizer manufacturing, and RP mining. Because of the mismatch among all stages in the supply chain and mismanagement within each stage, $10 \%, 30 \%$, and $60 \%$ P loss occurred during the whole P supply in RP mining, P-fertilizer manufacturing, and crop production (Fig. 3a). There is great potential to improve the PRE by integrating it in all stages in the whole supply chain. Thus, China provides strong support for the global prospect in the mitigation of P-related environmental costs. China's experience can be shared with and applied to similar regions, such as India.

\subsection{Knowledge-based P management based on crop demand}

The DADVA framework combines empirical knowledge, databases, and modelling tools to advance understanding of an integrated P-management strategy in the whole supply chain based on crop demand (Fig. 2). SFA was used to analyze the P flow of the whole supply chain, from RP mining to $\mathrm{P}$ use in crop production, to gain better insights into farmers' constraints.
Compared with FP, RP extraction in OPT1 was reduced by $18.3 \%$, and $28.1 \mathrm{~kg} \mathrm{ha}^{-1}$ of high-concentration and $7.0 \mathrm{~kg} \mathrm{ha}^{-1}$ of low-concentration chemical P were produced. $\mathrm{P}$ loss in the whole chain was reduced to $21.9 \mathrm{~kg} \mathrm{ha}^{-1}$. Only $10.7 \mathrm{~kg} \mathrm{P} \mathrm{ha}^{-1}$ was lost in crop production (Fig. 3b), which was almost half that in FP. Moreover, by combining the buildup and maintain approach with optimized chemical P types, $27.4 \mathrm{~kg}$ of RP extraction was needed in OPT2. P loss to the environment was only $2.4 \mathrm{~kg}$. More interestingly, $3.5 \mathrm{~kg}$ P from the soil was consumed by crops (Fig. 3c). The PRE in OPT1 was $53.0 \%$, an improvement of $14.3 \%$. It was further improved by $52.9 \%$ in OPT2 (Fig. 4a). The P footprint in OPT1 and OPT2 was reduced by $26.9 \%$ and $57.7 \%$, respectively (Fig. 4b).

\subsection{Rock phosphate consumption demand for grain production in China}

The average RP consumption in 31 Chinese provinces for grain production from 2005 to 2014 is presented in Fig. 5. At the national scale, RP consumption demand for grain production in China was 4.0 Mt. (Fig. 5a). Compared with FP, RP demand for gain production was reduced by $26 \%$ in OPT1 (Fig. 5b). By combining the build-up and maintain approach with optimized chemical P types, RP extraction in OPT2 was reduced by $58 \%$, and the largest decrease was found in North China. Medium-lowgrade RP extraction reduced by $39 \%$ in OPT1 but more than five times in OPT2 (Fig. S7). High-grade RP extraction in OPT2 was reduced by $75 \%$ (Fig. S8), and a significantly reduced dependence on high-grade RP for grain production in OPT2 was found in the North and Northeast China Plains (Fig. S8).

\subsection{Scenario analysis}

In China, economic expansion and population growth are leading to a significant increase in meat demand and subsequently for grain used as animal feed. China's population is expected to peak at 1.45 billion in 2030 (NHFPC, 2016). Rice, wheat, and maize production are thus predicted to increase to 218, 125, and 315 Mt., respectively, to meet the demand (Chen et al., 2014). To meet this production target, $5.3 \mathrm{Mt}$. of total RP will be needed in 2030 in FP, while $1.0 \mathrm{Mt}$. of medium-low-grade RP and 4.3 Mt. of high-grade RP will be mined (Fig. 6). However, if we reach the projected demand in 2030 with OPT1 and OPT2, the total RP could be reduced by $25 \%$ and $57 \%$, respectively (Fig. 6a). Moreover, medium-lowgrade and high-grade RP could be reduced by $30 \%$ and $25 \%$ by 2030 with OPT1, respectively (Fig. 6b). Medium-low-grade RP could be increased by $70 \%$ for OPT 2 compared with FP, but high-grade RP could be reduced by $75 \%$ (Fig. $6 \mathrm{c}$ ). This will alleviate the P-environmental crisis in the breadbasket region of China. 


\section{Rock phosphate mining}

(a)

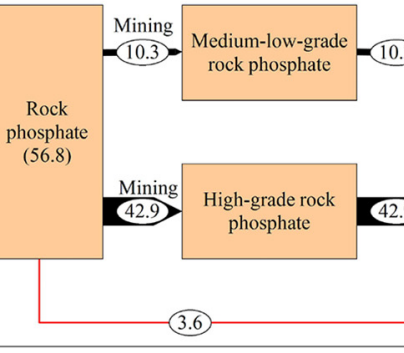

(b)

(c)
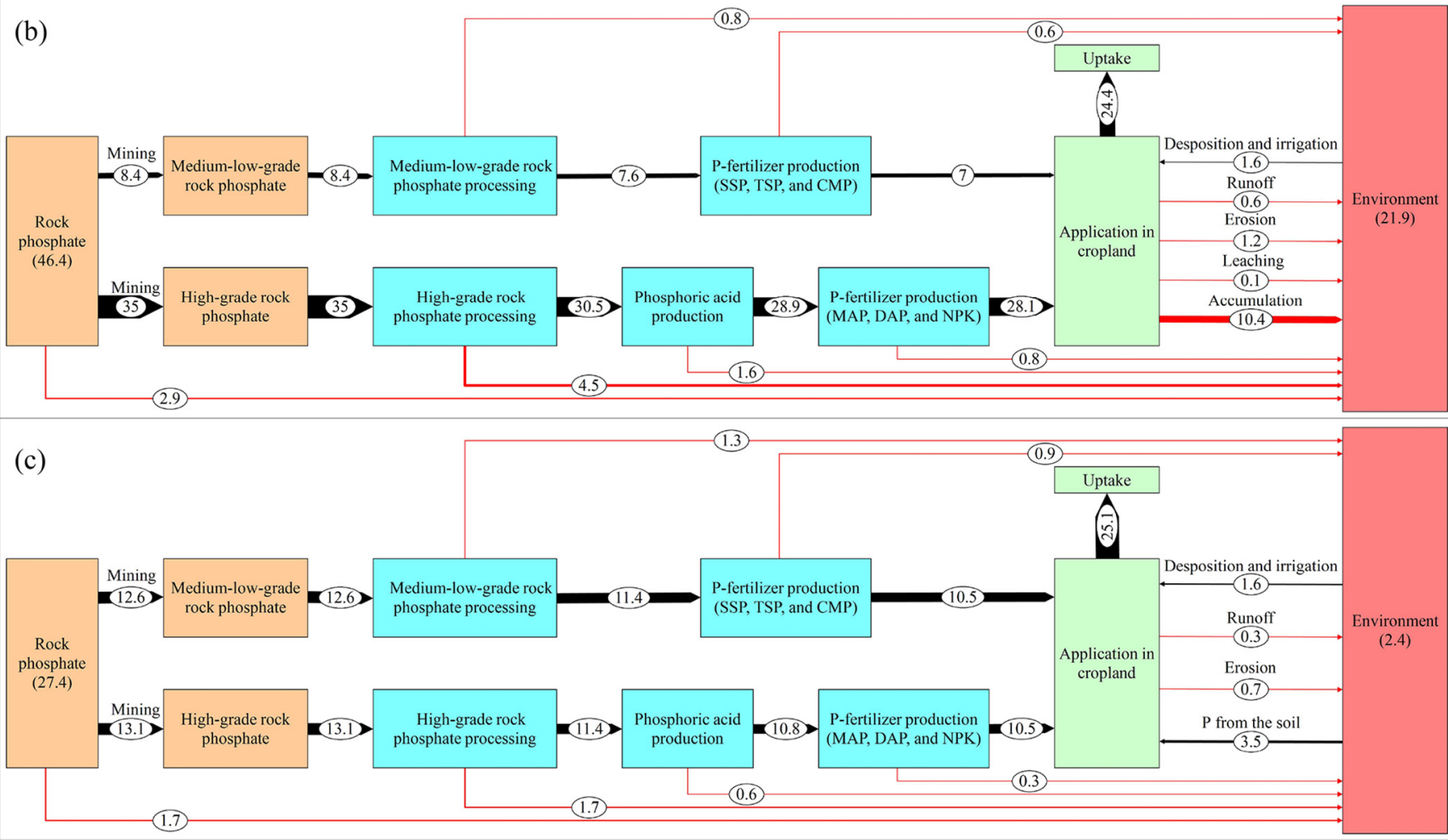

\section{Crop production}

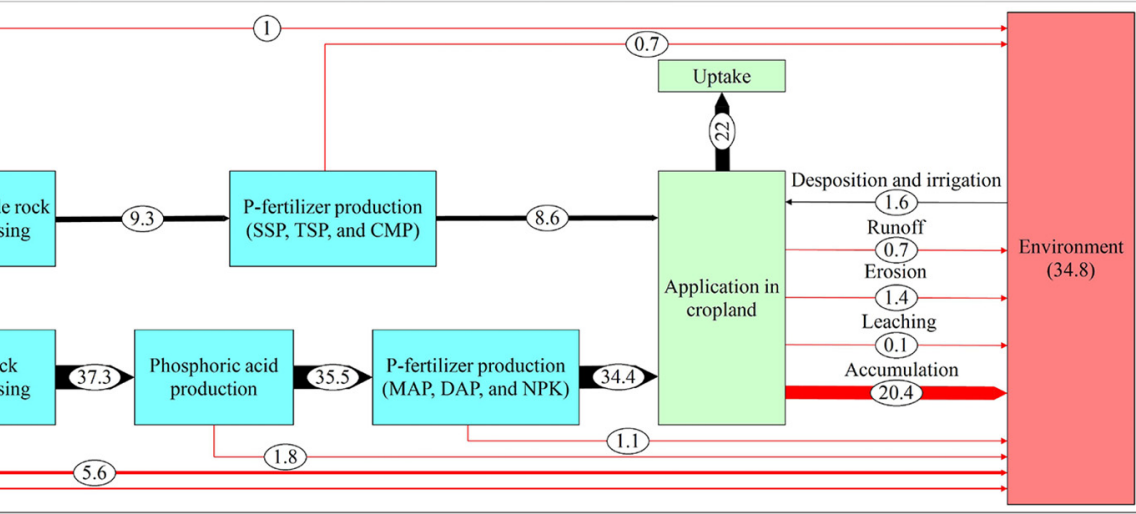

Unit: $\mathrm{kg} \mathrm{P} \mathrm{ha}^{-1}$

Fig. 3. Phosphorus (P) flow from rock phosphate extraction to grain production in China under different treatments: (a) FP, (b) OPT1, and (c) OPT2. FP, OPT1, and OPT2, respectively, represent mineral P use according to farmer practices, optimized use based on soil fertility and the soil-testing approach, and optimized use based on the principle of the build-up and maintain approach, coupled with chemical P-use intensity and types. MAP: monoammonium phosphate; DAP: diammonium phosphate; NPK: nitrogen, phosphorus, and potassium; SSP: single superphosphate; TSP: triple super phosphate; CMP: calcium magnesium phosphate.

\section{Discussion}

To produce enough food for a large and growing population while using P sustainably is one of the greatest challenges faced by farmers, fertilizer manufacturers, policymakers, and researchers today (Cordell and White, 2013). Effectively improving the PRE and reducing the reliance on RP reserves would be valuable. Our results demonstrated that crop production is the super-hotspot for $\mathrm{P}$ loss. The accumulated $\mathrm{P}$ was the major driver for P loss to the water bodies (e.g., runoff, erosion, and leaching) in the whole supply chain, and thus water eutrophication was quite common because of P loss (Liu et al., 2016). Meanwhile, P loss in developed countries such as Europe was only $2.8 \mathrm{~kg} \mathrm{P}^{-1} \mathrm{yr}^{-1}$ (Lun et al., 2018). Therefore, there exists a global challenge to tighten $\mathrm{P}$ recycling and reduce $\mathrm{P}$ loss in the supply chain (Chen and Graedel, 2016; Schneider et al., 2019). Based on the biological characteristics of crops, agronomic P-management practices, and chemical $\mathrm{P}$ supply and mining, we proposed that $\mathrm{P}$ mining should occur based on specific crop demand. We demonstrated that using a chemical P-fertilizer optimization management approach, the PRE would improve the whole supply chain $14.3-52.9 \%$ without any production penalty and hence reduce RP depletion risks (Fig. 4 and Table 1). Therefore, it is an effective approach to improve the PRE in the whole supply chain.

This approach, as well as key elements of the measures, could serve as references for other countries or situations. For instance, using the soiltesting approach, $45 \%$ of $\mathrm{P}$ could be saved in crop production (Fig. 3). Moreover, this approach has been widely used by farmers to boost crop yields in China since the 1980s (He et al., 2012). A build-up and maintenance approach suggested that chemical P-fertilizer should be managed to keep appropriate soil Olsen-P concentration in the root zone for higher PUE (Bai 


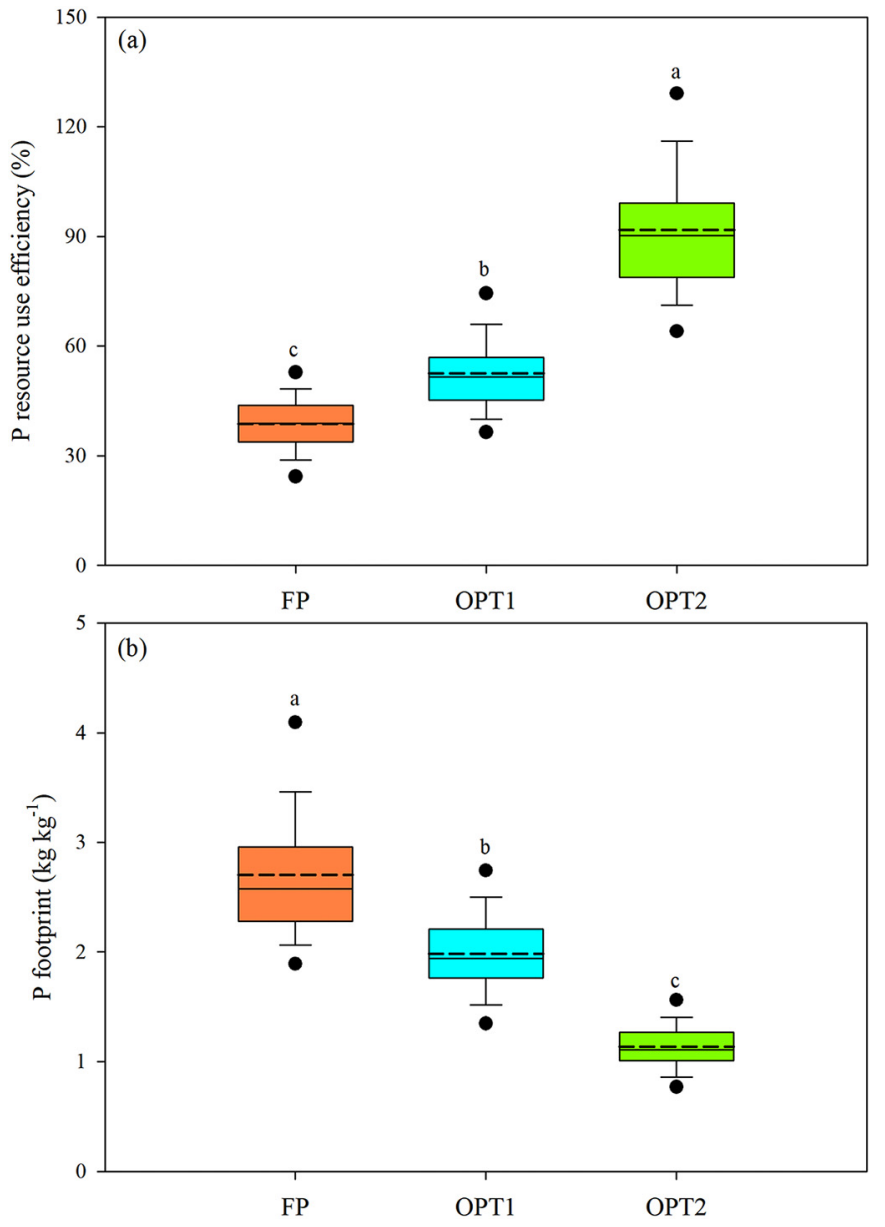

Fig. 4. Phosphorus (P) resource use efficiency (a) and $P$ footprint (b) under different treatments. FP, OPT1, and OPT2, respectively, represent mineral P use according to farmer practices, optimized use based on soil fertility and the soil-testing approach, and optimized use based on the principle of the build-up and maintain approach coupled with chemical P-use intensity and types.

et al., 2013). The ideal management system for sustainable $P$ use will utilize not only application rates but also appropriate $P$ sources. The formulation of water-soluble $\mathrm{P}$ and low water-soluble $\mathrm{P}$ has been recommended as an agronomically and economically effective method to increase the PUE in Asia, sub-Saharan Africa, and Latin America (Bindraban et al., 2020). The build-up and maintain approach, when combined with optimized fertilizer types, can help crop plants acquire P from the soil (Fig. 3).

RP mining based on the crops' $\mathrm{P}$ demand could help address the issues with grain yield, the PRE, and the RP crisis synergistically. In this study, the yield-response curve and the build-up and maintain approach with chemical P-fertilizer types were employed to optimize mineral fertilizer use in crop production. The yield-response curve helped secure high crop yields and optimize large-scale fertilizer use by considering economic gains and the distribution of fertilizers (Li et al., 2011); however, this approach largely ignored the soil's legacy nutrients (Li et al., 2015). In contrast, the build-up and maintain approach achieved better synchronization between crops' P demand and the soil's P supply throughout the cropgrowing season, and the soil's legacy P was fully considered. Relying on the soil's legacy $\mathrm{P}$ as a P source for crops is a very promising strategy for improving the efficiency, sustainability, and profitability of agricultural systems, as well as for reducing eutrophication risk (Rowe et al., 2015).

Many generic methods have been utilized to identify interventions to ensure sustainable P management. For instance, using a system-based strategy may help alleviate the RP crisis and food security in Europe: the 5R strategy-re-align $\mathrm{P}$ inputs, reduce $\mathrm{P}$ loss to water, recycle $\mathrm{P}$ into a bioresource, recover $\mathrm{P}$ from waste, and redefine $\mathrm{P}$ in food systems-has
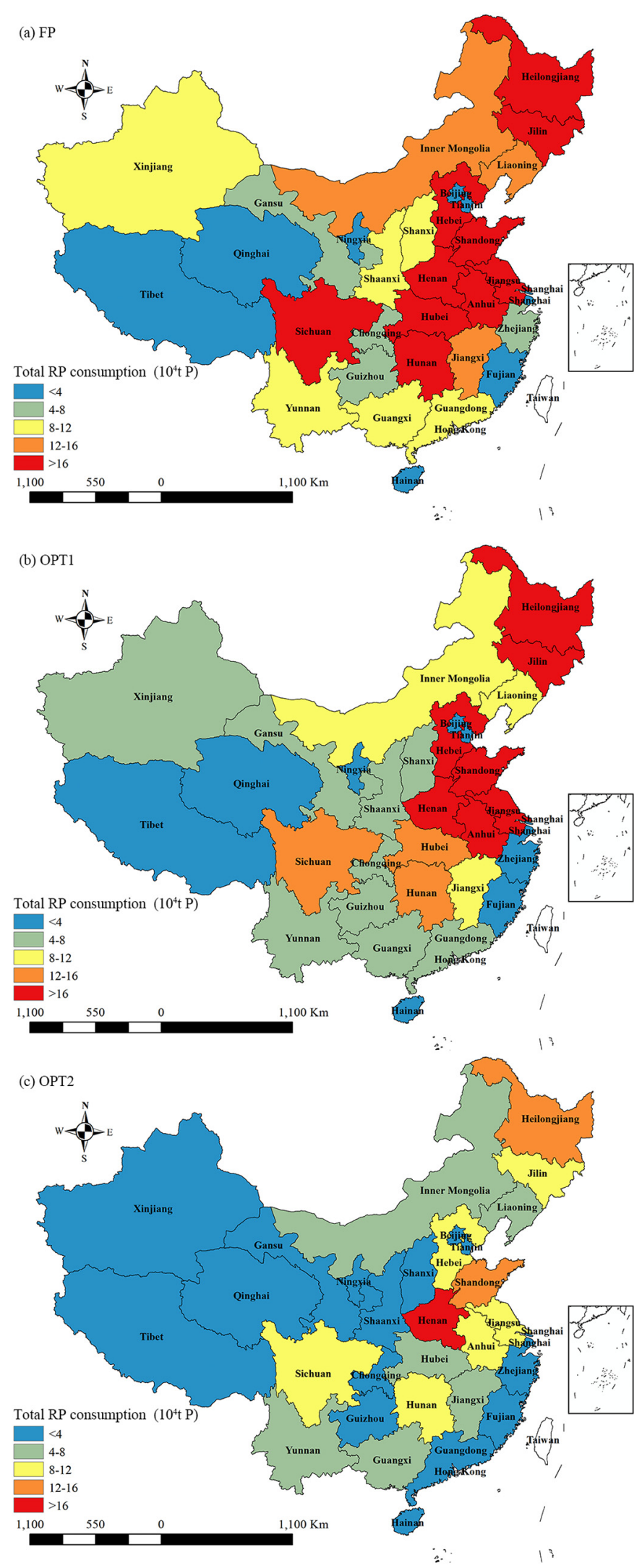

Fig. 5. Spatial variations of rock phosphate (RP) consumption for grain production from 2005 to 2014 in China: (a) FP, (b) OPT1, and (c) OPT2. FP, OPT1, and OPT2, respectively, represent mineral $\mathrm{P}$ use according to farmer practices, optimized use based on soil fertility and the soil-testing approach, and optimized use based on the principle of the build-up and maintain approach coupled with chemical P-use intensity and types. 

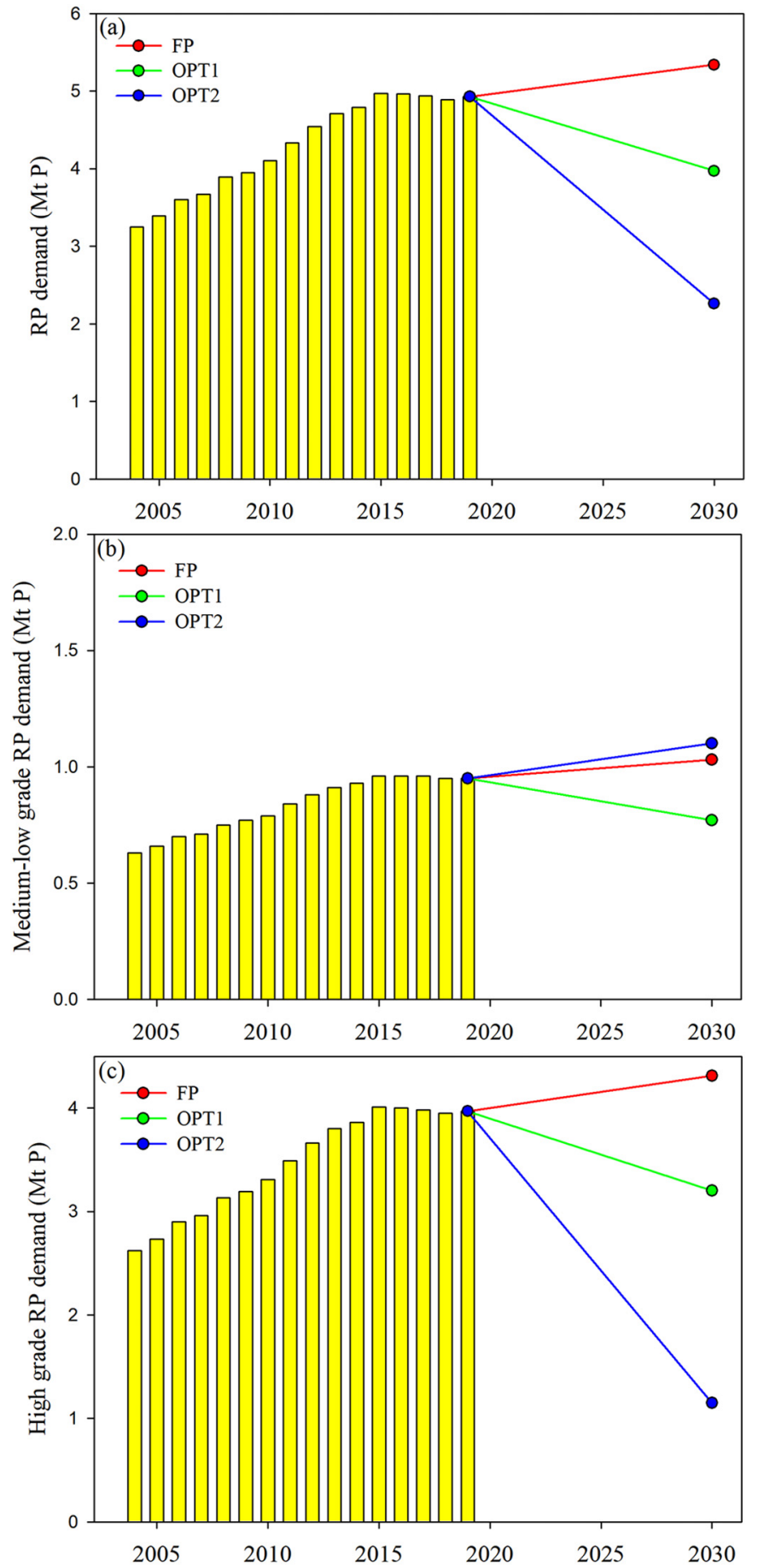

Fig. 6. Projected demand of rock phosphate (RP) to produce sufficient food to feed a large population by 2030 under different scenarios in China: (a) FP, (b) OPT1, and (c) OPT2. FP, OPT1, and OPT2 respectively represent mineral P use according to farmer practices, optimized use based on soil fertility and the soil-testing approach, and optimized use based on the principle of the build-up and maintain approach coupled with chemical P-use intensity and types.

recently been outlined as a blueprint for P stewardship and sustainability (Withers et al., 2008). In this study, we presented a DADVA theoretical framework that could provide a more advanced method and collaborative decision support to multi-stakeholders of the P supply chain. We demonstrated that crop production is the hotspot of $\mathrm{P}$ loss in the supply chain. Therefore, knowledge innovation in sustainable $\mathrm{P}$ use of crop production is a key approach to reducing $\mathrm{P}$ loss.
This knowledge-based management approach allowed us to obtain a complete picture of the supply chain in this study, which ensured that genuine problems were not ignored. Further, each stakeholder can make accurate, informed decisions based on their roles in the chain if they can access, share, and harmonize the data as well as ensure parameterization of social and health aspects. For instance, with DADVA, the PRE of OPT1 and OPT2 was $53.0 \%$ and $91.6 \%$, respectively. This can be increased up to $77 \%$ by using integrated measures, but this needs broad cooperation between miners, fertilizer plants, and farmers (Zhang et al., 2008).

A knowledge-based P management approach with DADVA would be effective for tightening P recycling along the whole supply chain. Advancing participatory innovation and technology will require investment from smallholder farmers, and stimulating smallholder action is a key step in changing their consciousness to achieve sustainable $\mathrm{P}$ management (Zhang et al., 2013). The framework also needs to be supported by technology. Within the national space, a key challenge in defining region-specific pathways for the sustainable development of $\mathrm{P}$ management would be synergistically combining improvements in technologies and management, reduction in P loss and waste, and P management changes based on crops' P requirements while considering local contexts and environmental pressures.

The conclusion that this study arrived at was based on tens of thousands of primary data from field trials under large-scale agro-ecological conditions. The higher level of granularity achieved in this manner increased the confidence level of the results. However, there is a high degree of variability in RP mining and chemical P-fertilizer manufacturing due to the varying sizes of chemical fertilizer companies in China (Zhang et al., 2013), whereas our study only considered partial SFA including RP mining, chemical P-fertilizer manufacturing, and crop production as the system scope. Some processes, such as the storage of fertilizers and the transportation of fertilizers to the field, were not considered owing to data unavailability. The technologies are also likely to be highly variable because of the influence of climate and environment, and the study could not provide an overall evaluation of them across various regions and multiple species. To address this limitation of the current study, future research could investigate the solution space more broadly and comprehensively to understand adaptative strategies by considering factors such as resources and environmental consequences. More evidence-based studies on improving the PRE through the integration of all stages in the P supply chain are also needed in practice, especially regarding the working mechanisms of cross-section cooperation.

\section{Conclusion}

Improving the PRE and reducing the threat to P resources are closely linked to not only crop production but also chemical P-fertilizer production. We show that the current P-management strategy with $43.1 \mathrm{~kg} \mathrm{ha}^{-1} \mathrm{P}$ input did not produce a higher yield, but rather a $34.8 \mathrm{~kg} \mathrm{ha}^{-1} \mathrm{P}$ loss with low PRE. Using the yield-response curve and build-up and maintain approach combined with optimized fertilizer types, we demonstrate great potential to improve the PRE for mitigation of the P crisis, and show that $\mathrm{P}$ footprint can be reduced and RP demand for grain production can be saved 1.3 Mt. and 3.0 Mt. without yield penalty with crop-demandoriented P supply chain through integration of crop production, chemical P-fertilizer manufacturing, and RP mining. A knowledge-based management theoretical framework was used to analyze P supply chains to explore ways to mitigate China's P crisis. This framework connects upstream P industries and crop production, addressing knowledge gaps and stakeholder involvement. The results indicated that the P management strategy should be developed on the basis of crop P requirements and must be considered from the whole supply chain perspective.

\section{CRediT authorship contribution statement}

Haiqing Gong: Methodology, Visualization, Writing - original draft. Yue Xiang: Methodology, Visualization, Writing - original draft. Jiechen Wu: Writing - review \& editing. Peteh Mehdi Nkebiwe: Writing - review \& editing. Gu Feng: Resources, Writing - review \& editing. Xiaoqiang 
Jiao: Supervision, Software, Validation, Writing - review \& editing. Fusuo Zhang: Supervision, Resources, Validation.

\section{Declaration of competing interest}

The authors declare that they have no known competing financial interests or personal relationships that could have appeared to influence the work reported in this paper.

\section{Acknowledgments}

This work was supported by the National Key R\&D Program of China (2017YFD0200200/0200206), and the Deutsche Forschungsgemeinschaft (DFG, German Research Foundation)-328017493/GRK 2366 (Sino-German International Research Training Group AMAIZE-P).

\section{Appendix A. Supplementary data}

Supplementary data to this article can be found online at https://doi. org/10.1016/j.scitotenv.2021.152739.

\section{References}

Bai, Z.H., Li, H.G., Yang, X.Y., Zhou, B.K., Shi, X.J., Wang, B., Li, D.C., Shen, J.B., Chen, Q., Qin, W., Oenema, O., Zhang, F.S., 2013. The critical soil P levels for crop yield, soil fertility and environmental safety in different soil types. Plant Soil 372 (1-2), 27-37. https:// doi.org/10.1007/s11104-013-1696-y.

Bindraban, P.S., Dimkpa, C.O., Pandey, R., 2020. Exploring phosphorus fertilizers and fertilization strategies for improved human and environmental health. Biol. Fertil. Soils 56 (3), 299-317. https://doi.org/10.1007/s00374-019-01430-2.

Brownlie, W.J., Sutton, M.A., Heal, K.V., Spears, B.M., 2021. Global actions for a sustainable phosphorus future. Nat. Food 2 (2), 71-74. https://doi.org/10.1038/s43016-021-00232-w.

Chen, M., Graedel, T.E., 2016. A half-century of global phosphorus flows, stocks, production, consumption, recycling, and environmental impacts. Glob. Environ. Chang. 36, 139-152 doi:110.1016/j.gloenvcha.2015.12.005.

Chen, X., Cui, Z., Fan, M., Vitousek, P., Zhao, M., Ma, W., Wang, Z., Zhang, W., Yan, X., Yang, J., Deng, X., Gao, Q., Zhang, Q., Guo, S., Ren, J., Li, S., Ye, Y., Wang, Z., Huang, J., Tang, Q., Sun, Y., Peng, X., Zhang, J., He, M., Zhu, Y., Xue, J., Wang, G., Wu, L., An, N., Wu, L., Ma, L., Zhang, W., Zhang, F., 2014. Producing more grain with lower environmental costs. Nature 514 (7523), 486-489. https://doi.org/10.1016/j.scitotenv.2014.12.101.

Chowdhury, R.B., Zhang, X., 2021. Phosphorus use efficiency in agricultural systems: a comprehensive assessment through the review of national scale substance flow analyses. Ecol. Indicat. 121, 107172. https://doi.org/10.1016/j.ecolind.2020.107172

Chowdhury, R.B., Moore, G.A., Weatherley, A.J., Arora, M., 2016. A novel substance flow analysis model for analysing multi-year phosphorus flow at the regional scale. Sci. Total Environ. 572, 1269-1280. https://doi.org/10.1016/j.scitotenv.2015.10.055.

Cordell, D., White, S., 2013. Sustainable phosphorus measures: strategies and technologies for achieving phosphorus security. Agronomy 3, 86-116. https://doi.org/10.3390/agronomy3010086.

Cui, Z., Zhang, H., Chen, X., Zhang, C., Ma, W., Huang, C., Zhang, W., Mi, G., Miao, Y., Li, X., Gao, Q., Yang, J., Wang, Z., Ye, Y., Guo, S., Lu, J., Huang, J., Lv, S., Sun, Y., Liu, Y., Peng, X., Ren, J., Li, S., Deng, X., Shi, X., Zhang, Q., Yang, Z., Tang, L., Wei, C., Jia, L., Zhang, J., He, M., Tong, Y., Tang, Q., Zhang, X., Liu, Z., Cao, N., Kou, C., Ying, H., Yin, Y., Jiao, X., Zhang, Q., Fan, M., Jiang, R., Zhang, F., Dou, Z., 2018. Pursuing sustainable productivity with millions of smallholder farmers. Nature 555, 363-366. https://doi.org/10.1038/nature25785.

He, P., Jin, J.Y., Pampolino, M.F., Johnston, A., 2012. Approach and decision support system based on crop yield response and agronomic efficiency. Plant Nutr. Fertil. Sci. 18 (2), 499-505. https://doi.org/10.11674/zwyf.2012.11248.

Jiang, S., Hua, F., Jarvie, H.P., Liu, X., Zhang, Y., Yuan, Z.W., Zhang, L., Liu, X., 2018. Phosphorus footprint in China over the 1961-2050 period: historical perspective and future prospect. Sci. Total Environ. 650, 687-695. https://doi.org/10.1016/j.scitotenv.2018.09.064.

Jiao, X.Q., Lyu, Y., Wu, X.B., Li, H.G., Cheng, L.Y., Zhang, C.C., Yuan, L.X., Jiang, R.F., Jiang, B.W., Rengel, Z., Zhang, F.S., Davies, W.J., Shen, J.B., 2016. Grain production versus resource and environmental costs: towards increasing sustainability of nutrient use in China. J. Exp. Bot. 67, 4935-4949. https://doi.org/10.1093/jxb/erw282.

Li, G., Huang, G., Li, H., Ittersum, M.V., Leffelaar, P.A., Zhang, F., 2016. Identifying potential strategies in the key sectors of China's food chain to implement sustainable phosphorus management: a review. Nutr. Cycl. Agroecosyst. 104 (3), 341-359. https://doi.org/10. 1007/s10705-015-9736-z.

Li, H., Huang, G., Meng, Q., Ma, L., Yuan, L., Wang, F., Zhang, W., Cui, Z., Shen, J., Chen, X., Jiang, R., Zhang, F., 2011. Integrated soil and plant phosphorus management for crop and environment in China: a review. Plant Soil 373, 157-167. https://doi.org/10.1007/ s11104-011-0909-5.

Li, H., Jian, L., Li, G., Shen, J., Zhang, F., 2015. Past, present, and future use of phosphorus in Chinese agriculture and its influence on phosphorus losses. Ambio 44 (Supplement 2), 274-285. https://doi.org/10.1007/s13280-015-0633-0.

Liang, S., Yu, Y., Kharrazi, A., Fath, B.D., Yang, Z., 2020. Network resilience of phosphorus cycling in China has shifted by natural flows, fertilizer use and dietary transitions between 1600 and 2012. Nat. Food 1, 365-375. https://doi.org/10.1038/s43016-020-0098-6.
Liu, X., Zhang, X., Herbert, S.J., 2010. Feeding China's growing needs for grain. Nature 465 (7297), 420. https://doi.org/10.1038/465420a.

Liu, X., Sheng, H., Jiang, S., Yuan, Z., Zhang, C., Elser, J.J., 2016. Intensification of phosphorus cycling in China since the 1600s. Proc. Natl. Acad. Sci. U. S. A. 113 (10), 2609-2614. https://doi.org/10.1073/pnas.1519554113.

Lun, F., Liu, J., Ciais, P., Nesme, T., Chang, J., Wang, R., Goll, D., Sardans, J., Penuelas, J., Obersteiner, M., 2018. Global and regional phosphorus budgets in agricultural systems and their implications for phosphorus-use efficiency. Earth Syst. Sci. Data 10 (1), 1-45. https://doi.org/10.5194/essd-10-1-2018.

Luo, Z.B., Ma, S.J., Hu, S.Y., Chen, D.J., 2017. Towards the sustainable development of the regional phosphorus resources industry in China: a system dynamics approach. Resour. Conserv. Recycl. 126, 186-197. https://doi.org/10.1016/j.resconrec.2017.07.018.

Ma, W., Lin, M., Li, J., Wang, F., Sisák, I., Zhang, F., 2011. Phosphorus flows and use efficiencies in production and consumption of wheat, rice, and maize in China. Chemosphere 84 (6), 814-821. https://doi.org/10.1016/j.chemosphere.2011.04.055.

Nanda, M., Kansal, A., Cordell, D., 2020. Managing agricultural vulnerability to phosphorus scarcity through bottom-up assessment of regional-scale opportunities. Agric. Syst. 184, 102910. https://doi.org/10.1016/j.agsy.2020.102910.

National Bureau of Statistics of China, 2016. China Statistical Yearbook. China Statistics Press. National Health and Family Planning Commission of the People's Republic of China (NHFPC), ). Chinese Population Is Supposed to Reach the Peak of 1.45 Billion in 2030.Available at: http://news.xinhuanet.com/live/2016-01/11/c_1117730833.htm (Accessed on 1 November 2016).

Peter, H., Koh, L., Guang, V.S., 2019. An integrated theoretical framework to enhance resource efficiency, sustainability and human health in agri-food systems. J. Clean. Prod. 120, 164-169. https://doi.org/10.1016/j.jclepro.2015.08.092.

Pizzol, M., Weidema, B., Brandão, M., Osset, P., 2015. Monetary valuation in life cycle assessment: a review. J. Clean. Prod. 86, 170-179. https://doi.org/10.1016/j.jclepro.2014.08.007.

Röös, E., Bajželj, B., Smith, P., Patel, M., Little, D., Garnett, T., 2017. Greedy or needy? Land use and climate impacts of food in 2050 under different livestock futures. Glob. Environ. Chang. 47, 1-12. https://doi.org/10.1016/j.gloenvcha.2017.09.001.

Rowe, H., Withers, P.A., Baas, P., Chan, N.I., Weintraub, M., 2015. Integrating legacy soil phosphorus into sustainable nutrient management practices on farms. Nutr. Cycl. Agroecosyst. 104 (3), 393-412. https://doi.org/10.1007/s10705-015-9726-1.

Sattari, S.Z., van Ittersu, M.K., Giller, K.E., Zhang, F., Bouwman, A.F., 2014. Key role of China and its agriculture in global sustainable phosphorus management. Environ. Res. Lett. 9 (5), 054003. https://doi.org/10.1088/1748-9326/9/5/0540.

Schneider, K.D., Martens, J.R.T., Zvomuya, F., Reid, D.K., Fraser, T.D., Lynch, D.H., O'Halloran, I.P., Wilson, H.F., 2019. Options for improved phosphorus cycling and use in agriculture at the field and regional scales. J. Environ. Qual. 48, 1247-1264. https:// doi.org/10.2134/jeq2019.02.0070.

Shen, J., Yuan, L., Zhang, J., Li, H., Bai, Z., Chen, X., Zang, W., Zhang, F., 2011. Phosphorus dynamics: from soil to plant. Plant Physiol. 156 (3), 997-1005. https://doi.org/10. 1104/pp.111.175232.

Simons, A., Solomon, D., Chibssa, W., Blalock, G., Lehmann, J., 2014. Filling the phosphorus fertilizer gap in developing countries. Nat. Geosci. 7 (1), 3. https://doi.org/10.1038/ngeo2049.

Tilman, D., Balzer, C., Hill, J., Befort, B.L., 2011. Global food demand and the sustainable intensification of agriculture. Proc. Natl. Acad. Sci. U. S. A. 108, 20260-20264. https://doi. org/10.1073/pnas.1116437108.

USGS, 2012. Phosphate Rock, Statistics and Information. Mineral Commodity Summaries. Available at:USGS, Reston, VA. http://minerals.usgs.gov/minerals/pubs/commodity/ phosphate_rock/mcs-2012-phosp.pdf.

Wang, M., Ma, L., Strokal, M., Ma, W.X., Kroeze, C., 2018. Hotspots for nitrogen and phosphorus losses from food production in China: a county-scale analysis. Environ. Sci. Technol. 52, 5782-5791. https://doi.org/10.1021/acs.est.7b06138.

West, P.C., Gerber, J.S., Engstrom, P.M., Mueller, N.D., Brauman, K.A., Carlson, K.M., Cassidy, E.S., Johnston, M., Macdonald, G.K., Ray, D.K., 2014. Leverage points for improving global food security and the environment. Science 345 (6194), 325-328. https://doi. org/10.1126/science.1246067.

Withers, P., Elser, J.J., Hilton, J., Ohtake, H., Schipper, W.J., Dijk, K.V., 2008. Stewardship to tackle global phosphorus inefficiency: the case of Europe. Ambio 44 (2), 193-206. https://doi.org/10.1007/s13280-014-0614-8.

Withers, P.J.A., Elser, J.J., Hilton, J., Ohtake, H., Schipper, W.J., van Dijkf, K.C., 2015. Greening the global phosphorus cycle: how green chemistry can help achieve planetary P sustainability. Green Chem. 17, 2087-2099. https://doi.org/10.1039/C4gc02445a.

Wu, H., Guo, L., Yuan, Z., Wang, S., 2016. Life cycle assessment of phosphorus use efficiency in crop production system of three crops in Chaohu watershed,China. J. Clean. Prod. 139, 1298-1307. https://doi.org/10.1016/j.jclepro.2016.08.137.

Yuan, Z., Jiang, S., Sheng, H., Liu, X., Hua, H., Liu, X., Zhang, Y., 2018. Human perturbation of the global phosphorus cycle: changes and consequences. Environ. Sci. Technol. 52 (5), 2438-2450. https://doi.org/10.1021/acs.est.7b03910.

Zhang, W., Tang, X., Feng, X., Wang, E., Li, H., Shen, J., Zhang, F., 2019. Management strategies to optimize soil phosphorus utilization and alleviate environmental risk in China. J. Exp. Bot. 48, 1167-1175. https://doi.org/10.2134/jeq2019.02.0054.

Zhang, W.F., Ma, W.Q., Ji, Y.X., Fan, M.S., Oenema, O., Zhang, F.S., 2008. Efficiency, economics, and environmental implications of phosphorus resource use and the fertilizer industry in China. Nutr. Cycl. Agroecosyst. 80 (2), 131-144. https://doi.org/10.1007/s10705-0079126-2.

Zhang, W.F., Dou, Z.X., He, P., Ju, X.T., Powlson, D., Chadwick, D., Norse, D., Lu, Y.L., Zhang, Y., Wu, L., 2013. New technologies reduce greenhouse gas emissions from nitrogenous fertilizer in China. Proc. Natl. Acad. Sci. U. S. A. 110, 8375-8838. https://doi.org/10. 1073/pnas.1210447110

Zhao, Y., Li, Z., Liu, M., Xiao, X., Wang, C., Sun, D., Lun, F., 2019. Phosphorus budgets and their associated environmental risks in the main apple orchard areas in China from 2006 to 2016. J. Agric. Environ. Sci. 38, 2779-2787. https://doi.org/10.11654/jaes. 2019-1078. 